\title{
Digital Literacy Enhancement Status in Kenya's Competency-Based Curriculum
}

\author{
Gioko Maina ${ }^{1}$ and Waga Rosemary ${ }^{2}$ \\ 1 Aga Khan Academy, Mombasa, Kenya \\ 2 Aga Khan Education Service, Kenya
}

\begin{abstract}
Digital literacy (DL) is a one of the competency recommended for educators to be embedded in the Kenyan Competency Based Curriculum (CBC) in preparation for learners for the 21st century skills. The Ministry of Education deployed devices to lower primary at a ratio of 1 to 1 . The aim of the research was to determine the level and frequency of embedding the digital literacy abilities after the teachers and school leaders in a 3-day preparation and 8 weeks of implementation with virtual support through Communities of learning.

The methodology was a self-administered survey which evaluated the seven abilities based on the level and frequency of implementation. The dot product of level and frequency were determined as a percentage. The analysis explored the average percentages and the relationship between level and frequency of implementation.

The findings revealed that there was a correlation between the level and the frequency of implementation. All abilities where at developing stage on average. The mode and mean on levels and frequency were on average similar apart from few cases where it was above. All the abilities had a bell curve on implementation with access, integrate and evaluate skewed to the right

It can be concluded that despite the deployment of devices there is still very low implementation of DL and there is a significant relationship between the level and frequency of implementation. There is need to interrogate possible factors to low implementation beyond devices and educator preparation with virtual support.
\end{abstract}

Keywords: Digital Literacy, Teacher Preparation, Competencies.

\section{Introduction}

\subsection{Purpose}

"Every child in grade 1 will have a computer the time they come into the school”, a government pronouncement during the pre-election meeting in Kenya. This political statement was the beginning of a nationwide supply tablets in grade 1 for all the students. The focus then was technology integration in pedagogy. Overtime this has transited to digital literacy which is a core competency in ongoing curriculum reforms. The reforms saw the investment on structural resources and teacher preparation. Schools were provided with tablets and pre-loaded routers and teacher 
were trained on competency-based curriculum which included digital literacy (DL) as one of the competencies.

The purpose of this study was to evaluate the level and frequency of implementation of the DL abilities to inform the next iteration of teacher preparation. The question to answer was to what extent is digital literacy enhanced in teaching and learning in schools.

\subsection{Background information}

The preparation of Digital literacy is base the description of the element and abilities

\section{ELEMENTS}

digital competence: skills, concepts approaches, attitudes, etc.

digital usage: the application of digital competence within a specific context (such as a school)

digital transformation: creativity and innovation in the digital domain.

\section{ABILITIES}

define: to understand and articulate the scope of an information problem to facilitate the electronic search for information

access: knowing about and knowing how to collect and retrieve information manage: applying an existing organizational or classification scheme

integrate: interpreting and representing information, including summarizing, comparing

evaluate: making judgments about the quality, relevance, usefulness, or efficiency of information

create information: generating information by adapting, applying, designing, inventing, or authoring information

communicate: disseminate information tailored to an audience in an effective digital format. [1]

The teachers were prepared on the elements and the abilities in an embedded approach alongside three other competencies of critical thinking and problem solving, creativity and imagination and communication and collaboration. Teachers were prepared for 3 days covering aspect of lesson planning, delivery and extensions. The implementation took 13 weeks with virtual support through WhatsApp communities of learning. The training culminated to a closing one-day reflection workshop where the teachers showcased their learning journey. The teachers were expected to enhance the DL ability in their lesson delivery. The study explores the teacher reflection on their level and frequency of implementation of the DL abilities.

\section{Literature Review}

The underlying themes of most work around DL are the need for individuals and organizations to respond to the challenges and opportunities offered by emerging technologies and the increasingly digitized and networked nature of society [2] .The 
concept of digital native does not define the generation that is currently graduating to become teachers in primary education [3].

Technology integration requires a special skill in which teachers review and change their pedagogy technology integration to facilitate literacy. The teacher preparation process varies on time, approach, quality of information and the nature of support after the face to face sessions. There are several factors which influence practice for the teachers to integrate technology. The factors ranged from age, experience, exposure of the teacher, infrastructural support in the school the curriculum. The experience of the teacher is informed by the teacher and how open minded they are towards innovative pedagogy and of teaching. The exposure of the teacher is informed to how well the teacher is exposed to devices different approaches of classroom instruction. The infrastructural support the setup in the school of electricity, access to devices, a support officer, instructional material availability and collaborative planning time. The curriculum structure facilitates opportunities for technology integration. Deeper and regular implementation would facilitate immersion and institutionalization of embedding the DL. Gioko and Kadzo advocates for mainstreaming of the practices for sustainability [4].

The implementation of new approaches ranges at different levels and frequency, but the aspiration is reaching the exemplary and proficient levels. WaGioko has identified time, peer support and refresher session as factors that support aspirations [5]. DL is described as a development process from access and functional skills to higher level capabilities and identity [6]. However, this will change depending on the context, so it also reflects how individuals can be motivated to develop new skills and practices in different situations.

Media literacy is not only the development or interpretive skills but also "involves a series of digital production skills that include the ability to create, to be critical and to contribute well as to consume" the digital content [7]. Moreover, digital media literacy and cultural skills are developed in networking and established on traditional literacy (reading \& writing), research, and critical-analysis skills of media [8]. The digital literacy involves knowledge creation as it is embed in pedagogy.

The emphasis of digital literacy can be built on the fact that society needs a configuration of well-developed communication and problem-solving skills that include these five digital media competencies (access, analyses and evaluate, create, reflect and act) [9]. These competencies are aligned with the focus used to prepare the teachers. The implementation is facilitated by the teachers one as a direct responsibility of their digital literacy, two as an instrument of their rights protection and finally as an essential aspect of their education [10].

\section{$3 \quad$ Methodology}

The data collection involved a self-administered peer validated survey which was exploring how the ability were enhance on delivery based on the level and frequency. The implementation meant the lesson delivery. The levels looked at the implementors and the frequency looked at the implementation across lesson, subject and timelines 
The responses of were analyzed to explore the level and frequency of implementation as well as their relationships. The responses were treated as a case and the group of responses presented a multi-case approach

Table 1. The descriptors for level and frequency of implementation

\begin{tabular}{|c|c|c|c|c|c|}
\hline & $\begin{array}{l}\text { Needs Support } \\
\text { (1) }\end{array}$ & $\begin{array}{l}\text { Emerging } \\
(2)\end{array}$ & $\begin{array}{l}\text { Developing } \\
\text { (3) }\end{array}$ & $\begin{array}{l}\text { Proficient } \\
(4)\end{array}$ & $\begin{array}{l}\text { Exemplary } \\
\text { (5) }\end{array}$ \\
\hline Level & $\begin{array}{l}\text { Only the } \\
\text { trained } \\
\text { teachers are } \\
\text { demonstrating } \\
\text { some of the } \\
\text { abilities in } \\
\text { some of the } \\
\text { lessons }\end{array}$ & $\begin{array}{l}\text { Only the Trained } \\
\text { teachers in the } \\
\text { school are } \\
\text { demonstrating } \\
\text { the abilities } \\
\text { across some } \\
\text { lessons }\end{array}$ & $\begin{array}{l}\text { All the } \\
\text { teachers in the } \\
\text { school are } \\
\text { demonstrating } \\
\text { the abilities } \\
\text { across some } \\
\text { lessons }\end{array}$ & $\begin{array}{l}\text { All the } \\
\text { teachers in } \\
\text { the school } \\
\text { are } \\
\text { demonstrati } \\
\text { ng the } \\
\text { abilities } \\
\text { across all } \\
\text { the lessons }\end{array}$ & $\begin{array}{l}\text { All the teachers } \\
\text { in the school are } \\
\text { demonstrating } \\
\text { the abilities } \\
\text { across all the } \\
\text { lessons and the } \\
\text { community } \\
\text { engagement }\end{array}$ \\
\hline Frequency & Very Rarely & Rarely & Sometimes & Often & Very Often \\
\hline
\end{tabular}

The variable was scored against a Likert scale and supported by evidence. The individual scores were validated against the evidence reviewed in a school group. The school's scorings were presented and reviewed across school's based on the evidence provided. There were peer validation and school's validation of the scores across schools.

The data was analyzed across abilities and within abilities. The levels distribution both for implementation and frequency were analyzed within the abilities. MannWhitney test was used to analyze five-point Likert items for two groups (Level and frequency) [11]. Likert scales can be included in a larger group of measures since they are based on the idea that some underlying phenomenon can be measured by aggregating an individual's rating of his/her feelings, attitudes, or perceptions related to a series of individual statements or items [12]. Likert-type items fall into the ordinal measurement scale. Descriptive statistics recommended for ordinal measurement scale items include a mode or median for central tendency and frequencies for variability.

The correlation between implementation and frequency, the mean and median were analyzed across abilities to determine the enhancement across abilities.

\section{$4 \quad$ Findings and Discussions}

The Digital Literacy abilities were implemented at different levels. The following is a description of the level of implementation and frequencies.

Define which is to understand and articulate the scope of an information problem to facilitate the electronic search for information had mode 3 and median 3 in implementation and mode 3 and median 3 in frequency with a correlation of 0.735 
between implementation and frequency. There was both a max of exemplary and needs support in both implementation and frequency. The distribution of the Implementation and frequency was as shown in figure 1

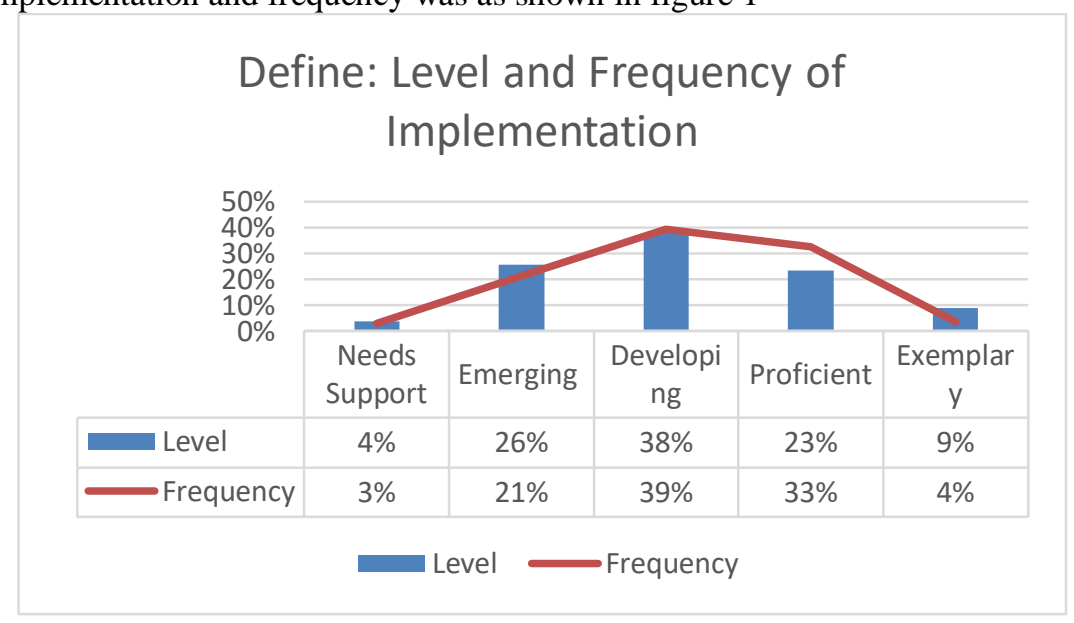

Fig. 1. Distribution of Level and Frequency -DEFINE

In define developing was with most teachers at $38 \%$, with the lowest needs support at $4 \%$. Less than $10 \%$ of the teachers were at exemplary level. Define is mainly theoretical and its clear 33\% of the teacher had a good grasp (proficient and exemplary) of the information. $66 \%$ of the teachers are yet to reach the acceptable levels. Being a theoretical aspect, it can be inferred that the information was available and accessible. For emerging and below the frequency was lower tank the implementation levels, while for developing and above the frequency was well above the implementation level apart from exemplar. Those at an exemplary level were implementing well but the frequency was not matching the implementation level. This could be the risk element where wider level of implementation brought in a lower level of implementation due to the resources used as well as the number of people involved.

Access, which is about knowing, and knowing how to collect and retrieve information. The was mode 3 and median 3 in implementation and mode 3 and median 3 in frequency with a correlation of 0.817 between implementation and frequency. The distribution of the Implementation and frequency was as shown in figure 2

Most teachers (68\%) topped the charts at developing and proficient at the level of implementation with the frequency topping at $73 \%$ collectively. The lowest were close to each other's at between $6 \%$ and $7 \%$ for needs support and exemplary respectively in level of implementation and $4 \%$ and $3 \%$ on frequency respectively. $41 \%$ (level) and 39\%( frequency) of the teachers where at the acceptable level (proficient and exemplary) leaving 59\% (level) and 61\% (frequency) at below expectation. The percentage of those in need of support was higher than define This could be attributed to the fact that access was not mainly theoretical, but it had and 
aspect of explaining how the access information. The functional parts required more than the information to be able to describes the function. The frequencies for emerging, developing and proficient where higher than the implementation levels. Needs support and exemplary had a lower frequency as compare to the implementation.

\section{Access: Level and Frequency of Implementation}

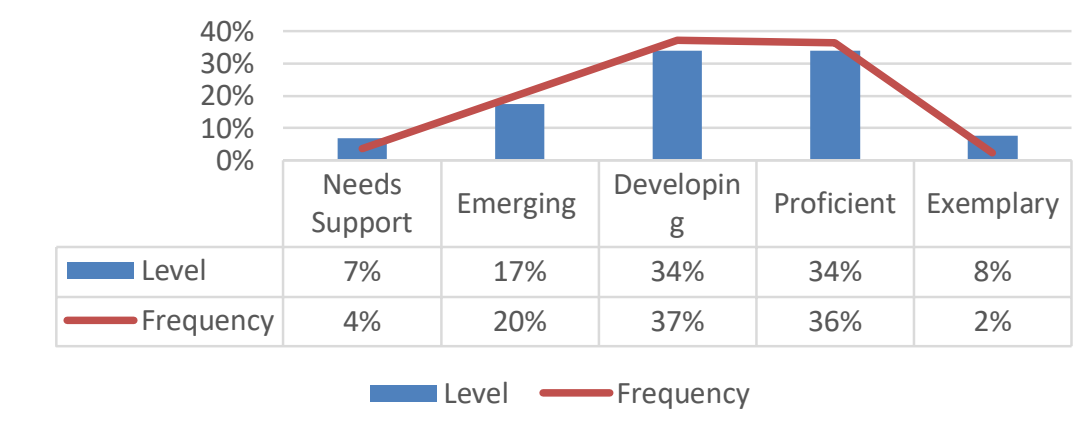

Fig. 2. Distribution of Level and Frequency -ACCESS

Manage which is about applying an existing organizational or classification scheme. The implementation had mode 3 and median 3 and frequency mode 3 and median 3 with a correlation of 0.810 between implementation and frequency.

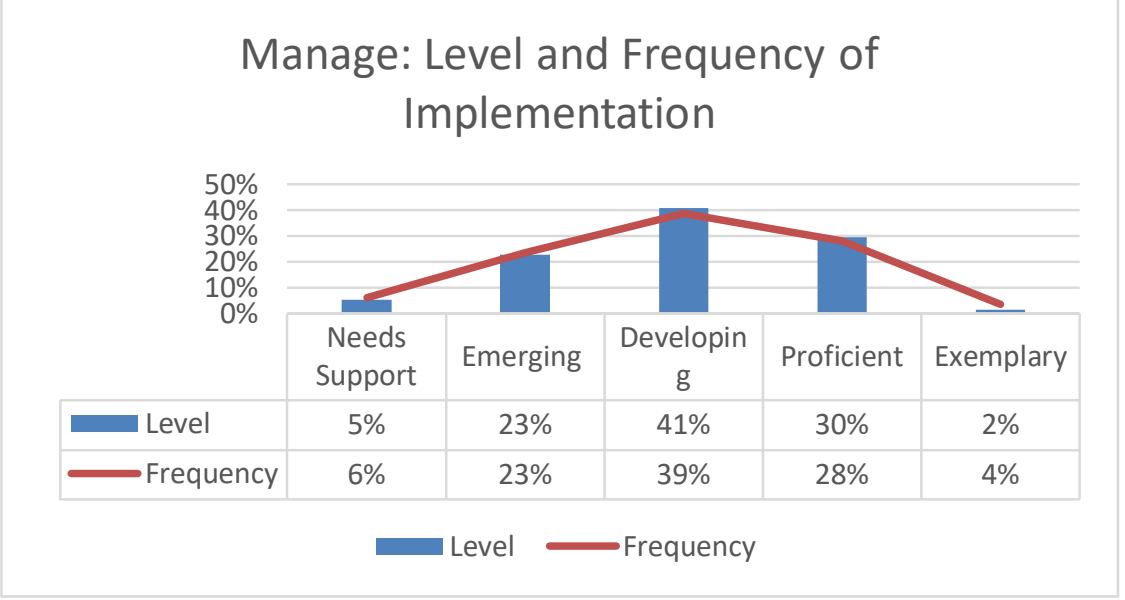

Fig. 3. Distribution of Level and Frequency -MANAGE

Manage which is a more practical ability had the highest percentage at both level and frequency at $41 \%$ and $39 \%$ respectively. The lowest was exemplary at $1 \%$ (level) and $4 \%$ (frequency). $40 \%$ (level) and 33\% (frequency) where at acceptable level 
proficient and exemplary. 60\% (level) and 66\% (frequency) of implementation was below expectation (Developing, emerging and needs support). This means that for functional abilities the levels of implementation for emerging, developing and proficient where lower than those of needs support and exemplary. This means that those who were not getting it right and those who were doing very well we're doing it more frequently than their level of implementation. This could be attributed to the fact that when the levels were low it was only the trained teacher who was doing it and hence they could be doing it more frequently comparatively as they did not have peer to support or guide them. On the other hand, those who were developing to proficient had a high implementation level which could have led to them feel that many people are doing it and hence the low frequency compared to the levels.

Integrate which is about interpreting and representing information, including summarizing, comparing. The implementation had mode 3 and median 3 and frequency mode 3 and median 3 with a with a correlation of 0.779 between implementation and frequency. The distribution of the Implementation and frequency was as shown in figure 4

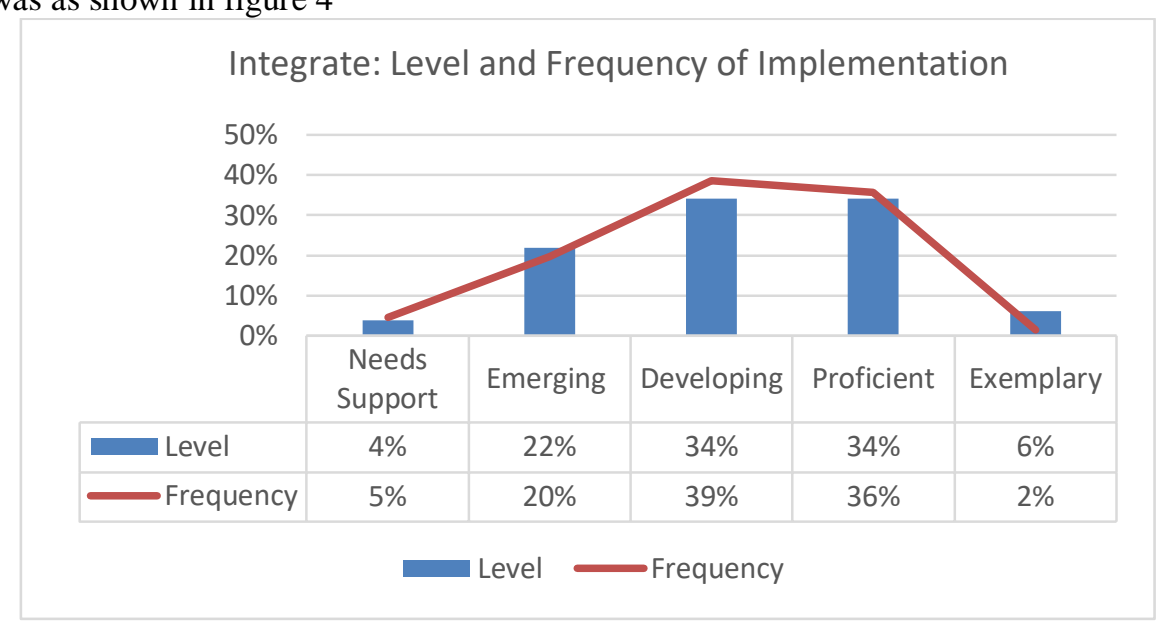

Fig. 4. Distribution of Level and Frequency -INTEGRATE

Developing and Proficient tied at 34\% with exemplary at 6\%.\%. 40\% where at proficient and developing. Emerging and needs support where at combined at 25\%. The frequencies for exemplary and emerging where lower compared to the respective implementation levels. Needs support and developing and proficient had a higher frequency compare to their respective implementation levels Integration is functional and more demanding on handling information, organizing information and presenting information. At $40 \%$ the number that can do well is low.

Evaluate which is about making judgments about the quality, relevance, usefulness, or efficiency of information. The implementation had mode 3 and median 3 and frequency mode 3 and median 3 with a with a correlation of 0.805 between implementation and frequency. The distribution of the Implementation and frequency was as shown in figure 5 
For evaluation, proficient was at 39\% with exemplary at 6\% giving a total of acceptable abilities at $45 \%$. Developing was at $29 \%$ with emerging and need support having a combine values of $20 \%$. The frequency was higher than implementation level only on developing stage and needs support. The rest it was lower than the implementation levels. Evaluation was meaning making from information which is critical in decision making however only $45 \%$ where in the acceptable levels.

Evaluate: Level and Frequency of Implementation

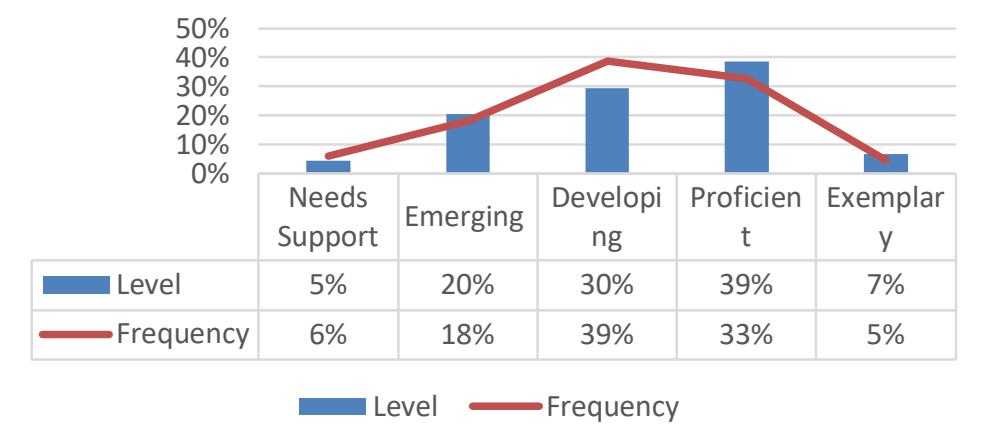

Fig. 5. Distribution of Level and Frequency -EVALUATE

Create information which is about generating information by adapting, applying, designing, inventing, or authoring information. There was both a max of exemplary and needs support in both implementation and frequency. The implementation had mode 3 and median 3 and frequency mode 3 and median 3 with a with a correlation of 0.829 between implementation and frequency. There was both a max of exemplary and needs support in both implementation and frequency. The distribution of the Implementation and frequency was as shown in figure 6

\section{Create: Level and Frequency of Implementation}

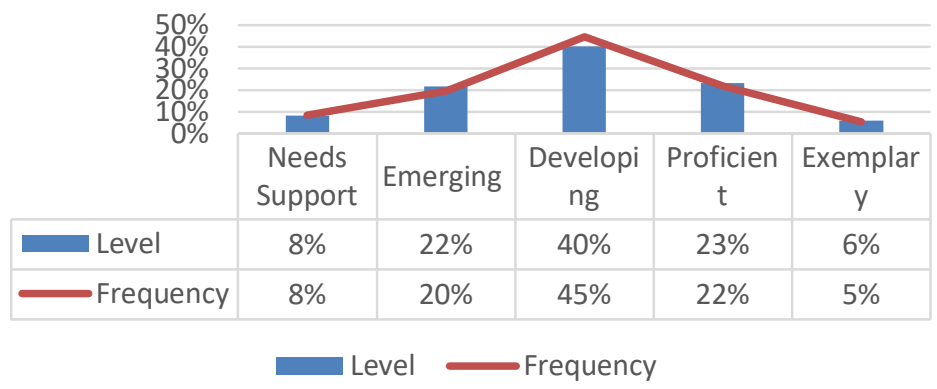

Fig. 6. Distribution of Level and Frequency -CREATE 
Create had developing being the highest at $40 \%$. Proficient and exemplary had a combined value of $30 \%$ with emerging and needing support at a combined value of $30 \%$. The frequency was only higher than the implementation level at developing. Need support and exemplary has equal values for frequency and implementation levels. Emerging and proficient has low frequency compare with the implementation. There is a higher number of developing (10\%) than those who can do as per the requirement. There is more teacher who $60 \%$ who are below the par. Creating requires resources and knowledge of how to. There is a tendency in school to download information based on the nature of the curriculum. Opportunities to create are very minimal and they could be attributed by the low level compounded with the skills.

Communicate which is about disseminate information tailored to an audience in an effective digital format. The implementation had mode 3 and median 3 and frequency mode 3 and median 3 with a with a correlation of 0.842 between implementation and frequency. The distribution of the Implementation and frequency was as shown in figure 7.

\section{Communication: Level and Frequency of Implementation}

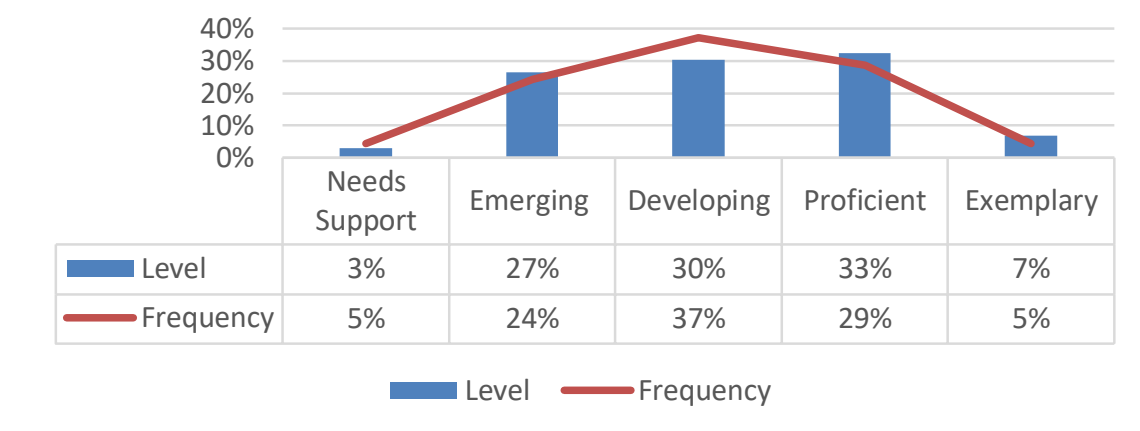

Fig. 7. Distribution of Level and Frequency -COMMUNICATION

Communication had emerging, developing and proficient all above 25\%. Proficient and exemplary has a combine value of 39\%. Developing was at 31\% with emerging and needing support at a combine value of $29 \%$. The frequency where high in developing as compare with implementation. All the other abilities had a lower frequency compared to implementation. At 39\% communication was quite low. Communication beyond presentation requires connectivity. The connectivity in Kenya schools are either low or nonexistence in majority of the public schools. 
Table 1. Correlation between level and frequency of implementation

\begin{tabular}{|c|c|c|c|c|c|c|}
\hline Define & Access & Manage & Integrate & Evaluate & Create & Communicate \\
\hline 0.735881 & 0.817588 & 0.810722 & 0.779751718 & 0.805371 & 0.829218 & 0.842057203 \\
\hline
\end{tabular}

Table 1 show a consistent correlation between implementation levels and frequency of implementation with a range of 0.104 is clear that one influence the other, the more the implementation the higher the frequency of implementation through it varied in some abilities at different levels of competencies.

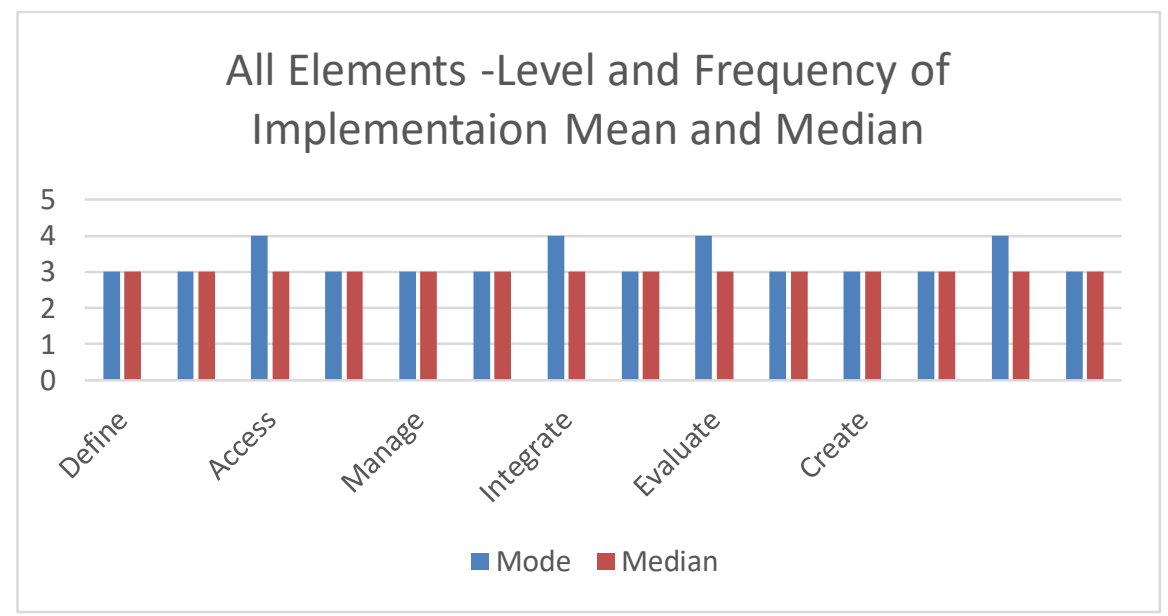

Fig. 8. All Elements Mean and Median for levels and Frequency

The relationship is further emphasized by the mode and the median most of them being at the same value for frequency and the levels of implementation.

In summary for abilities that have a symmetrical shape in the graph the those who were at proficient and beyond anger on average of $33 \%$ with a range of 9 . The abilities were skewed to the right and average of $42 \%$. The implementation level and frequency are interdependent and in developing the frequency was always higher than the implementation. In other abilities the relationships depended on the type of abilities and the nature of the ability and the factors that influence its functionality. Abilities are influenced by resources, support and the nature whether knowledge based, skill based, or competency based.

\section{$5 \quad$ Conclusion and Recommendation}

\subsection{Conclusion}

Despite equipping schools with devices and having trained the percentage of teacher at proficient level and above is very low at 36\% meaning out of 3 teachers only one is at par with the basic requirements. There are several abilities in digital literacy which 
are either knowledge, skill, or competency based. At knowledge base, define was at $33 \%$ with and equal number at developing. The skill-based which required resources such as manage, create where at the lowest at 30\%. The competency based which demanded functionality and had impact on decision making such as access, integration and evaluation were at an average of $42 \%$. Much of this result are based on several factors such as access and utility. Despite the devices being in the school it is through access and utility that would facilitate the homing in on these abilities. The curriculum especially the assessment drives pedagogy and hence its nature would influence the enhancement of the abilities.

\subsection{Recommendation}

The following are the suggesting for recommendation

Schools should increase utility of the devices in them pedagogy

The assessment method should be restructuring to demand the abilities hence their enhancement.

Resource based abilities needs to be facilitate, aspects of connectivity, projectors for presentations might enhance some of the abilities.

The level of implementation drives the frequency therefore more teacher in the school across the subjects and year levels should be encouraging to implement to facilitate the frequency.

There is need for a qualitative study to address the needs support teacher to establish aspects that are inhibiting their abilities enhancement.

\section{References}

1. British Council (b), "Teaching Digital Literacy Facilitators Manual," British Council, Nairobi, 2016.

2. A. Littlejohn, H. Beetham and L. McGill, "Learning at the digital frontier: a review of digital literacies in theory and practice," Journal of computer assisted learning, vol. 28, no. 6, pp. 547-556, 2012.

3. M. Prensky, Digital Natives, Digital Immigrants., vol. 9(5), On the Horizon.: MCB University Press, 2001.

4. M. Gioko and L. Kadzo, "Curriulum developmnet for embedding digita literacy om Kenyan Schools," in Conference Proceeding Open Conference on Computers in Education OCCE 2018, Linz, Austria, 2018.

5. M. WaGĩokõ, Tranfer of Educational Leadership Skiills-Making it Happen, United State: Patridge, 2016.

6. R. Sharpe and H. Beetham, "Understanding students' uses of technology for learning: towards creative appropriation," Rethinking learning for the digital age: how learners shape their experiences, pp. 85-99, 2010.

7. T. Flew, New media: An introduction, 4th ed ed., Melbourne, VIC, Australia:: Oxford University Press., (2014). 
8. H. Jenkins, R. Purushotma, M. Weigel, K. Clinton and A. J. Robison, Confronting the Challenges of Participatory Culture: Media Education for the 21st Century., Cambridge, MA: The MIT Press, 2009.

9. R. Hobbs, Digital and media literacy: A plan of action, Washington, D.C.: The Aspen Institute, 2010.

10. A. Gionés-Valls and M. Serrat-BrustengaLa, "La gestiön de la identidad digital: una nueva habilidad informacional y digital," textos universitaris de biblioteconomla i documentaci6, vol. 6, no. 24, pp. 1-15, 2010.

11. J. de Winter and D. Dodo, "Five-Point Likert Items: t test versus Mann-WhitneyWilcoxon," Practical Assessment, Research and Evaluation, vol. 15, no. 11, 2010.

12. L. Cohen, L. Manion and K. Morrison, Research Methods in Education, 7th ed., London, UK: Routledge,, 2011.

13. UNESCO, Integrating Transversal Competencies in Education Policy and Practice, 2013. 